\title{
Normalização dos termos em pesquisas na educação e tecnologias: contribuição à Ciência
}

\author{
Daniel Mill, Erika Giacometti-Rocha, Patrícia M. P. Falcão \\ Universidade Federal de São Carlos (UFSCar) - Campus de São Carlos - Centro de \\ Educação em Ciências Humanas (CECH) - Rod. Washington Luís, km 235 - 13565905 \\ mill@ufscar.br, erikagiacometti@gmail.com, patricia.mirellaf@gmail.com
}

O grupo de Estudos e Pesquisas sobre Inovação em Educação, Tecnologias e Linguagens (Horizonte), tem por objetivo estudos e pesquisa sobre Inovações em Educação, Tecnologias e Linguagens e busca os fundamentos técnico-científicos da educação, com base na melhoria do ensino-aprendizagem pela inovação tecnológica e linguagens. Como exemplos de trabalhos desenvolvidos pelo grupo, apresentamos as linhas de pesquisa em Educação a Distância / Linguagem, Cognição, Tecnologia e Educação. Os órgãos fomentadores são CNPq e CAPES.

Recentemente o Grupo Horizontes organizou duas bases de dados de periódicos e teses, como resultado parcial de pesquisas sobre $\mathrm{EaD}$ e docência virtual, englobando outros importantes temas da área de Educação. Para a primeira base de dados (Base Teses), o Grupo Horizontes coletou e catalogou 1.540 teses de doutorado, defendidas em oito importantes Programas de Pós-Graduação em Educação (PPGE) brasileiros. Foi registrado um total de 6.829 termos-chave para o grupo de teses catalogadas. Na segunda base de dados (Base Periódicos), o Grupo Horizontes catalogou e organizou 3.988 artigos, publicados em 11 periódicos brasileiros qualificados com A1 ou A2 pelo Qualis Capes. No total, esses artigos possuem 14.809 termos-chave. Utilizamos essas duas bases para identificar quais trabalhos têm sido publicados com interesse direto ou indireto na temática Tecnologias da Informação e da Comunicação.

Especificamente, a apresentação do painel tem por objetivo demonstrar que as pesquisas científicas que abordam as influências das "Novas" Tecnologias de Informação e Comunicação no processo ensino-aprendizagem têm apresentado diversas denominações. Essa pluralidade dificulta pesquisas posteriores e se dissemina em projetos educacionais. O presente trabalho analisou essas terminologias e seus desdobramentos nos trabalhos acadêmicos e nos documentos oficiais do MEC.

Para isso foi construída uma tabela com todos os termos e abreviações utilizados pelas produções acadêmicas analisadas referindo-se a Tecnologias de Informação e de Comunicação. De maneira resumida, destacamos 44 terminologias diferentes e 11 abreviações distintas para se referir ao mesmo objeto, o que demonstra claramente a necessidade de que haja uma concordância terminológica específica para tais tecnologias a fim de garantir a autenticidade para futuras pesquisas. 